\title{
Perinatal Stroke and Apparent Life-Threatening Event: A Case Report
}

\author{
Antonella Palmieri1, Martina Finetti², Marta Bertamino², Laura Banov ${ }^{3}$, \\ Margherita Mancardi', Giovanni Morana ${ }^{5}$, Salvatore Renna ${ }^{1}$ \\ ${ }^{1}$ Emergency Department, IRCCS Gaslini, Genoa, Italy \\ ${ }^{2}$ Pediatric Reumatology Unit, IRCCS Gaslini, Genova, Italy \\ ${ }^{3}$ Hemostasis and Trombosis Unit, IRCCS Gaslini, Genova, Italy \\ ${ }^{4}$ Neurology Unit, IRCCS Gaslini, Genova, Italy \\ ${ }^{5}$ Neuroradiology Unit, IRCCS Gaslini, Genova, Italy \\ Email: antonellapalmieri@ospedale-gaslini.ge.it, martina81@tiscali.it, martabertamino@libero.it, \\ banov@ospedale-gaslini.ge.it, margheritamancardi@ospedale-gaslini.ge.it, \\ giovannimorana@ospedale-gaslini.ge.it, salvatorerenna@ospedale-gaslini.ge.it
}

Received 28 July 2014; revised 24 August 2014; accepted 13 September 2014

Copyright (C) 2014 by author and Scientific Research Publishing Inc.

This work is licensed under the Creative Commons Attribution International License (CC BY). http://creativecommons.org/licenses/by/4.0/

(c) (i) Open Access

\section{Abstract}

To analyze how the multidisciplinary clinical, biohumoral, instrumental approach to ALTE (Apparent Life Threatening Event) episode may discover cardiovascular disease in the newborn. Introduction: In the first year of life ALTEs concern $0.8 \%$ of access to Pediatric Emergency Department. The cause of apparent life-threatening events (ALTEs) in infants reflects a differential diagnosis that includes an array of congenital or acquired disorders. Approximately $10 \%-25 \%$ of apparent life-threatening events may remain unexplained following a thorough evaluation. Case report: B. E., a 2-month-old child, in wellbeing, shortly before meal, during sleep, was not responsive to repeated stimulations; he was hypotonic and unresponsive. About 15 minutes later, he presented a normal tone and state of consciousness. Evaluating the referred symptoms, diagnostic protocol for ALTE was started; the Angio-MRI brain performed as second line analysis showed a focal gliotic lesion at left striatal area. The cardiological evaluation with echocardiography detected a pervium foramen ovale (PFO), with minimum shunt left-right direction. At least, biohumoral tests revealed protrombin gene heterozygosis mutation. Conclusion: Apparent Life-Threatening Events are first manifestation of stroke in infant. Discussion: This report discloses how the multidisciplinary clinical approach is essential in ALTE. The exact management of ALTE patients is very important in situations like this, when the concomitant disease is rare. In fact, arterial stroke incidence in children $>28$ days of life is estimated between 1.2 and 7.9 cases/100,000 children/year. However, in the last 20 years, we observed an increased incidence of stroke, probably related to two main causes: a greater attention for this disease and a major survival of children with pathology that arrange for stroke thanks to a better prevention. In conclusion, it's a funda- 
mental multidisciplinary approach even in following months after the events.

\title{
Keywords
}

\author{
Perinatal Stroke, Apparent Life-Threatening Events, Pediatric, Emergency, Pro-Thrombotic Factor, \\ Congenital Heart Defect
}

\section{Introduction}

By definition, an apparent life-threatening event (ALTE) refers to a sudden event, often characterized by apnea or other abrupt changes in the child's behavior [1]. Symptoms of an ALTE include one or more of the following: apnea, change in color or muscle tone, coughing, or gagging. The most frequent complaint was cyanosis in 12 $(67 \%)$ and apnea in $8(44 \%)$ patients [2]. These episodes may necessitate stimulation or resuscitation to arouse the child and reinitiate regular breathing.

The incidence of ALTEs of presumably healthy infants is unknown, because demographic data are derived from cases in which children are admitted to emergency departments and because of marked variability in the clinical presentations. The incidence of ALTE is reported to be 1.57 to 2.46 in 1000 live birth [3].

Most ALTEs occur in children younger than one year with a peak incidence occurring between one week and two months of age [4]. Parker and Pitetti (2011) [5] reviewed the children presenting to an emergency department of a large children's hospital with a diagnosis of ALTE and founded a mortality rate of $0.5 \%$.

In the first year of life Apparent Life Threatening Events are $0.8 \%$ of access to emergency department in Children Hospital [6], still representing a multidisciplinary challenge, first of all because $99 \%$ of patient comes to medical attention in wellness. The cause of Apparent Life-Threatening Events (ALTEs) in infants reflects a differential diagnosis that includes an array of congenital or acquired disorders. Approximately $10 \%-25 \%$ of Apparent Life-Threatening Events may remain unexplained following a thorough evaluation. Commonly, the problems are digestive (up to $50 \%$ ), neurologic $(30 \%)$, respiratory $(20 \%)$, cardiac $(5 \%)$, and endocrine or metabolic (less than 5\%). In this context it appears necessary as a centralized approach in advanced center.

The situation is further complicated in view of the small contribution that the instrumental and laboratory tests can provide. Another unavoidable aspect is the emotional impact that these events may have on the family, in particular for fear of a possible recurrence. Therefore, the management of infant with ALTE is difficult both for clinical features and for emotional contest. A piecemeal approach to the problem may finally determine an imbalance in the use of resources, resulting in a large number of examinations, inappropriate admissions and readmissions.

In 1996 [7], the Study Group for SIDS of the Italian Society of Pediatric had formulated a proposal for clinical management of children with a history of ALTE, which was subsequently revised in a Consensus Conference held in Florence in 2001. The Conference made a consensus document that had been reviewed by a pool of experts within the Study Group SIDS/ALTE, with the intent to update the scientific knowledge on the subject, to make the most consistent clinical/instrumental approach to these patients and to outline future directions of research (GL SIP 2010 [8]).

In this article we report our examination of a case of ALTE that occurs in a presumably healthy infant and we present a significant example of the applicability of this diagnostic/therapeutic path.

\section{Clinical Report}

A two months old child was referred to our Emergency Department for a suspected Apparent Life Threatening Event. He was the first born of non-consanguineous parents. The mother was affected by hypothyroidism; his great-grandfather and the great-grandmother passed away at 52 and 54 because of a heart condition. Cousins affected by syncopal episodes occurred at 7 years and 2 days of life.

B. E. was born after a physiological pregnancy. His neonatal weight was $3400 \mathrm{~kg}$, normal adaptation for extra uterine life, artificial feeding during normal neonatal period.

In wellbeing, shortly before meal, during sleep, the child was not responsive to repeated stimulations; he was hypotonic and unresponsive. About 15 minutes later, he presented a normal tone and state of consciousness.

E. was therefore admitted to our Emergency Department; the patient clinical examination was negative. The 
anterior fontanelle was normotensive. Capillary refill time, muscle tone and reflexes were normal. The cardiac activity was rhytmic and abdomen treatalbe. Weight: $5310 \mathrm{Kg}\left(50^{\circ}\right)$, length $64 \mathrm{~cm}\left(>95^{\circ}\right)$, Cranial Circumference $38.5 \mathrm{~cm}\left(25^{\circ}\right)$, Body Temperature $36.7^{\circ} \mathrm{C}$.

Evaluating the referred symptoms, diagnostic protocol for ALTE was started:

Biohumoral and instrumental exams of first and second levels: (negative or normal): blood tests (hemochrome with leucocytes count, CRP, glycemia, hepatic and kidney activity indicators, urine exam and urine culture, occult test; nasal and pharyngeal swab; EEG and ECG. PT, APTT, fibrinogen, protein S and C, AT III, antiphospholipid antibodies). We found a heterozygosis mutation of prothrombin 20210.

Significant examinations:

1) Cranial ultrasonography: hyper echoic left caudate nuclei.

2) Angio-MRI brain: focal lesion at striatal left by previous vascular based lesion (lenticulostriate left arterial territory). The study did not document MRA alterations of the main components of the arterial circulation of intracranial vessels, but a tortuous course of tortuous course of left carotid artery at the transition between the cervical and petrous area (Figure 1).

3) Hemostasis and thrombosis evaluation: "no indication to start secondary prophylaxis with ASA, due to the age of the patient (he has passed the critical period for thrombotic risk, which is the first month of life) and not sure correlations between the finding of tortuosity of the internal carotid and the previous ischemic event. Moreover, the heterozygous FII mutation constitutes additional thrombotic risk in certain situations but in this clinical context does not constitute indication for prophylaxis."

In the suspect of an ALTE episode in patient with previous stroke were performed third level analysis:

Cardiological evaluation with echocardiography: patent foramen oval, with minimum shunt left-right direction.

During the recovery, the child didn't presented hypotonic events or loss of consciousness; vital signs with normal parameters. According to hemostasis expertand cardiologist, no treatment was started, but only a careful clinical, biohunoral and instrumental surveillance. The patient was discharged in wellness. As scheduled in ALTE-protocol information was provided on the home management of the events; was also performed practical course of cardiopulmonary resuscitation.

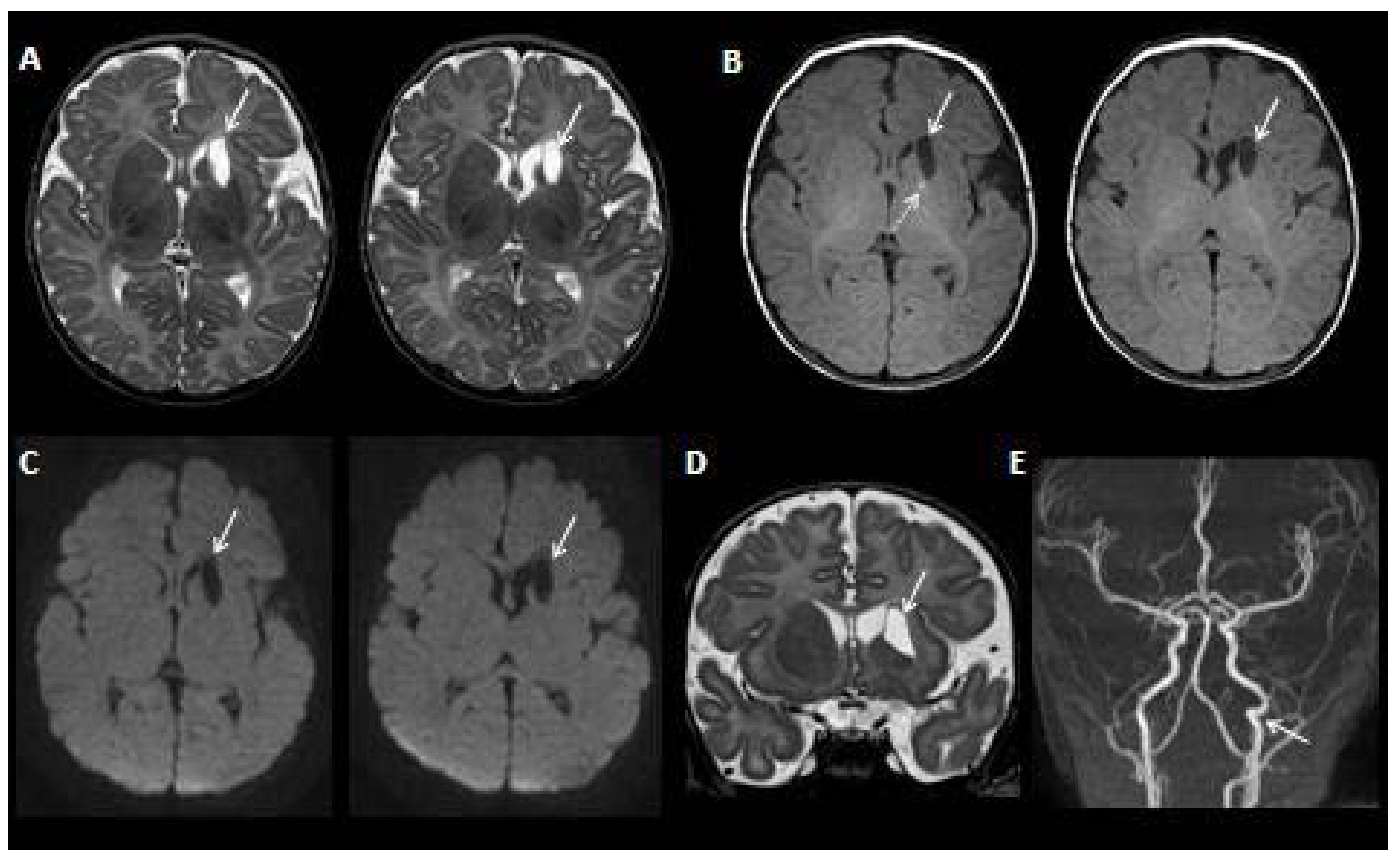

Figure 1. MRI and angio-MRI: T2-image (A) and T1 image (B) show the presence of left striatal lesion (arrow) with secondary dilatation of omolateral frontal corn. Calcific point lesion (dashed arrow). Corresponding to ischemic outcome (C) we observe increase diffusion (arrow). T2 Coronal image (D) demonstrates head caudate nucleus and putamen involvement. Angio-MRI study (E) doesn't evidence endocranic circle vessels alterations. Tortuous course of left carotid artery (arrow). 


\section{Discussion}

This report discloses how the multidisciplinary clinical approach is essential in Apparent Life-Threatening Events. The decision to admit an ALTE patient is rather difficult, for the previous reason: the children's age, the family anxiety, the medical history not always clear with the following risk to emphasize or minimize symptoms. Literature showed only few recommendations for patients' recovery criteria [9].

Recommendations published in 2004 by the European Society for the Study and Prevention of Infant Death (ESPID), based on ten years of literature evidences, say that the decision to admit to hospital depends on clinical history and clinical examination after the critic episode [10].

The admission to the hospital is necessary when the episode requires resuscitation supporter or when clinical conditions are not stationary.

Preterm children ( $<40$ week of gestational age) are higher exposed at events like bradycardia or apnea greater than 30 seconds and therefore they need a more careful surveillance, whilst children with age $>1$ month with only one ALTE episode without resuscitation, may be discharged after a first examination in emergency Department.

To sum up, even if we have not distinct criteria for hospital admission, we can define on the basis of clinical experience the following parameters of choice:

1) Patient age (first 30 days of life).

2) Preterm children (EPC $<43$ sett).

3) Clinical conditions instable at the moment of clinical assessment.

4) Event meal unrelated.

5) Sleep event.

6) Acute event.

7) Relapse of apparent life-threatening event.

8) resuscitation necessity.

9) Poor familiar compliance.

Among these parameters, the child age and the familiar compliance assume particularly importance. The less important events are those related to meal (within 30 minutes), the first and spontaneously solved event. The exact management of ALTE patients is very important in situation like this, when the concomitant disease is rare to [11]. In fact, arterial stroke incidence in children $>28$ days of life is estimated between 1.2 and 7.9 cases/100,000 children/year [12] [13]. Arterial ischemic stroke is reported to be more common than hemorrhagic stroke in children [14]. However, in the last 20 years, we observed an increased incidence of stroke, probably related to two main causes: a greater attention for this disease and a major survival of children with pathology that arrange for stroke thanks to a better prevention [15]. Gupta et al. in 2009 reported the case of two ALTE patients with very early magnetic resonance imaging (MRI) demonstrating a unilateral thalamic infarction [16]. The role of MRI in detecting cerebral lesion and in assessing the clinical outcome in ALTE patients is postulated in some recent reports; in fact, the report of Christophe C. et al. demonstrated that MRI could be helpful to assess the neurologic outcome as early as 3 days after the event when combined with the score of the electrophysiological investigations [17]. In conclusion, it's a fundamental multidisciplinary approach even in following months after the events [18].

\section{Conclusion}

We have analyzed the management of syncopal episode in patient with previous stroke, foramen ovale and heterozyogosis factor II gene. We have reported the importance of a multidisciplinary team in this kind of patients.

\section{References}

[1] Tieder, J.S., Altman, R.L., Bonkowsky, J.L., Brand, D.A., Claudius, I., Cunningham, D.J., DeWolfe, C., Percelay, J.M., Pitetti, R.D. and Smith, M.B. (2013) Management of Apparent Life-Threatening Events in Infants: A Systematic Review. The Journal of Pediatrics, 163, 94-99, e1-e6.

[2] Kadivar, M., et al. (2013) Apparent Life-Threatening Events in Neonatal Period: Clinical Manifestations and Diagnostic Challenges in a Pediatric Referral Center. Iranian Journal of Pediatrics, 23, 458-466.

[3] Kiechl-Kohlendorfer, U., Hof, D., Peglow, U.P., et al. (2005) Epidemiology of Apparent Life Threatening Events. Ar- 
chives of Disease in Childhood, 90, 297-300. http://dx.doi.org/10.1136/adc.2004.049452

[4] Santiago-Burruchaga, M., Sãnchez-Etxaniz, J., Benito-Fernãndez, J., et al. (2008) Assessment and Management of Infants with Apparent Life-Threatening Events in the Paediatric Emergency Department. European Journal of Emergency Medicine, 15, 203-208. http://dx.doi.org/10.1097/MEJ.0b013e3282f4d13a

[5] Parker, K. and Pitetti, R. (2011) Mortality and Child Abuse in Children Presenting with Apparent Life-Threatening Events. Pediatric Emergency Care, 27, 591-595. http://dx.doi.org/10.1097/PEC.0b013e3182225563

[6] Davies, F. and Gupta, R. (2002) Apparent Life Threatening Events in Infants Presenting to an Emergency Department. Emergency Medicine Journal, 19, 11-16.

[7] Gallone, G.C., et al. (1996) La gestione del bambino con ALTE (Apparent Life-Threatening Event). RivItalPed.

[8] SIP (2010) Apparent Life-Threatening Events (ALTE)—Linea Guida Diagnostico-Assistenziale.

[9] Claudius, I., et al. (2007) Do All Infants with ALTE Need to Be Admitted? Pediatrics, 119, 679-683.

[10] Tieder, J.S., et al. (2008) Variation in Inpatient Resource Utilization and Management of Apparent Life-Threatening Events. The Journal of Pediatrics, 152, 629-635, e1-e2.

[11] Hall, K.A. and Zalman, B. (2005) Evaluation and Management of Apparent Life-Threatening Events in Children. American Family Physician, 71, 2301-2308.

[12] Lynch, J.K., Hirtz, D.G., DeVeber, G. and Nelson, K.B. (2002) Report of the National Institute of Neurological Disorders and Stroke Workshop on Perinatal and Childhood Stroke. Pediatrics, 109, 116-123. http://dx.doi.org/10.1542/peds.109.1.116

[13] Agrawal, N., Johnston, S.C., Wu, Y.W., Sidney, S. and Fullerton, H.J. (2009) Imaging Data Reveal a Higher Pediatric Stroke Incidence than Prior US Estimates. Stroke, 40, 3415-3421. http://dx.doi.org/10.1161/STROKEAHA.109.564633

[14] Lynch, J.K. and Han, C.J. (2005) Pediatric Stroke: What Do We Know and What Do We Need to Know? Seminars in Neurology, 25, 410-423. http://dx.doi.org/10.1055/s-2005-923535

[15] Shah, S. and Sharieff, G.Q. (2007) An Update on the Approach to Apparent Life-Threatening Events. Current Opinion in Pediatrics, 19, 288-294. http://dx.doi.org/10.1097/MOP.0b013e32815745a9

[16] Gupta, S., Fernandez, D., Siddiqui, A., Lin, J.P., Garside, L. and Lim, M. (2009) Thalamic Infarct Presenting as Apparent Life-Threatening Event in Infants. Acta Paediatrica, 98, 2002-2005. http://dx.doi.org/10.1111/j.1651-2227.2009.01491.x

[17] Christophe, C., Boutemy, R., Christiaens, F., Fonteyne, C., Ziereisen, F. and Dan, B. (2000) Value of Brain MR Imaging in Infants with a Severe Idiopathic Apparent Life Threatening Event. Journal of Radiology, 81, 25-32.

[18] Stratton, S.J., Taves, A., Lewis, R.J., Clements, H., Henderson, D. and McCollough, M. (2004) Apparent Life-Threatening Events in Infants: High Risk in the Out-of-Hospital Environment. Annals of Emergency Medicine, 43, 711-717. http://dx.doi.org/10.1016/j.annemergmed.2003.10.038 
Scientific Research Publishing (SCIRP) is one of the largest Open Access journal publishers. It is currently publishing more than 200 open access, online, peer-reviewed journals covering a wide range of academic disciplines. SCIRP serves the worldwide academic communities and contributes to the progress and application of science with its publication.

Other selected journals from SCIRP are listed as below. Submit your manuscript to us via either submit@scirp.org or Online Submission Portal.
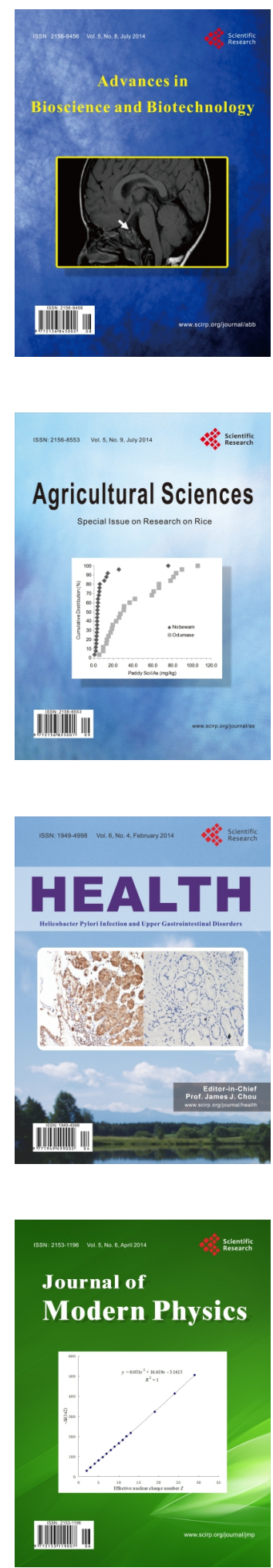
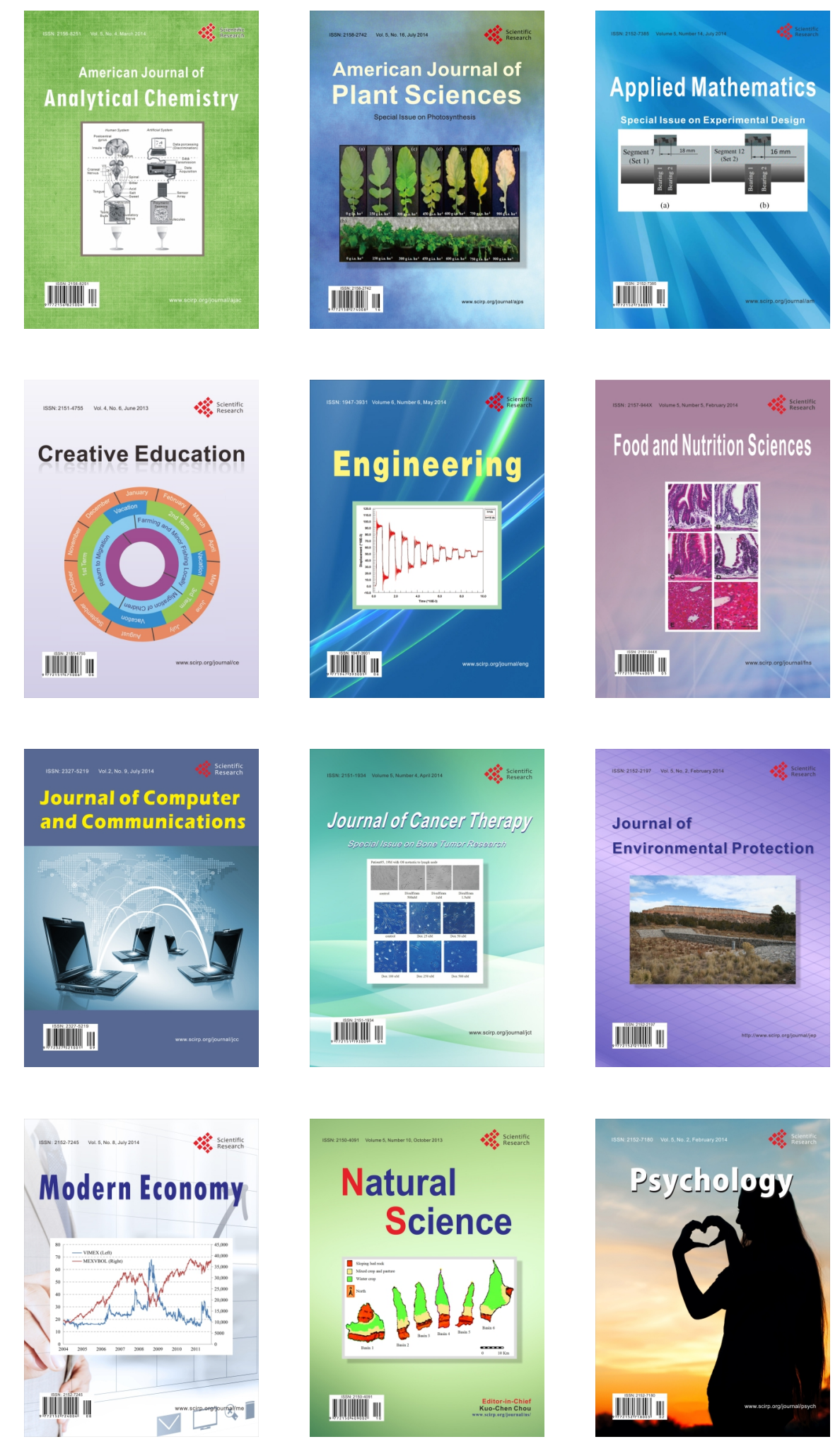